\title{
VIABILIDADE DO FÍGADO BIOARTIFICIAL UTILIZANDO HEPATÓCITOS HUMANOS IMUNOPROTEGIDOS POR MACROENCAPSULAÇÃO
}

\author{
ASSESSMENT OF BIOARTIFICIAL LIVER USING HUMAN HEPATOCYTES \\ IMMUNOPROTECTED BY MACROENCAPSULATION
}

\author{
João Eduardo Leal Nicoluzzi,TCBC-PR'; J João Carlos Domingues Repka²; Luiz Carlos Almeida Rocha; \\ Antonio Carlos Ligocki Campos, TCBC-PR ${ }^{4}$; Pedro Ernesto Caron, TCBC-PR ${ }^{5}$ Rolland Parc ${ }^{6}$
}

\begin{abstract}
RESUMO: Objetivo: O transplante de hepatócitos xenogênicos encapsulados pode ser utilizado no futuro em situações como a insuficiência hepática fulminante. Porém, observa-se perda precoce da expressão de genes hepatocitários específicos em hepatócitos humanos. O objetivo deste estudo é avaliar a influência da resposta imunológica na perda da expressão genética hepatocitária de hepatócitos humanos encapsulados e transplantados em ratos. Método: Hepatócitos humanos foram isolados de fragmentos hepáticos, encapsulados em fibras e transplantados em ratos. Nos dias 3, 7 e 14 após o transplante as fibras foram coletadas e avaliadas a morfologia por microscopia óptica e eletrônica, e a expressão dos genes por biologia molecular. O ARNm da albumina humana foi quantificado por RT-PCR e Northern blot. A resposta imunológica contra os hepatócitos foi avaliada através do ADN hepatocitário na busca de apoptose do núcleo celular e pelo aumento da expressão do $\mathrm{CMH}$ de classe I. Resultados: Os aspectos morfológicos dos hepatócitos mantiveram-se normais até o sétimo dia após o transplante. Não se observaram células envolvidas com resposta imunológica do receptor nas fibras. Os transcritos da albumina foram detectados até D-14. Entre os dias 3 e 7 estavam em 30\% em relação ao dia 0. A análise do ADN mostrou bandas preservadas sem a presença de fenômenos de apoptose nos diferentes dias. Não ocorreu aumento da expressão do CMH de classe I. Conclusões: Hepatócitos humanos encapsulados e transplantados em ratos permanecem viáveis apesar da diminuição da expressão de determinados genes. Este fenômeno, não se deve à resposta imunológica do receptor, mas ao próprio processo de isolamento celular (Rev. Col. Bras. Cir. 2004; 31(5): 311-317) - ISSN 0100-6991.
\end{abstract}

Descritores: Transplante de fígado; Hepatócito; Fígado artificial; Materiais biocompatíveis.

\section{INTRODUÇÃO}

O transplante hepático ortotópico constitui atualmente tratamento de escolha para doença hepática grave ou terminal. Esta intervenção comporta grande risco operatório, o paciente é submetido a tratamento imunossupressor por toda a vida e o custo desta terapia é elevado. Ressalta-se também que, no nosso meio, a doação de órgãos não condiz com a demanda, acarretando aumento na fila de espera, com conseqüentes agravos do estado clínico destes pacientes e piores resultados dos transplantes, razões pelas quais, certas equipes começaram a recorrer a alternativas tais como o doador vivo ou o split liver.

O transplante de hepatócitos isolados como recurso para suprir insuficiência hepática poderia ser, em certos casos, alternativa ao transplante com fígado inteiro. Principalmente em casos de hepatite fulminante, a assistência hepática através da reposição de hepatócitos isolados, poderia dar tempo à regeneração hepática ou mesmo, de se obter um ór- gão isogrupo de qualidade, funcionando neste caso, como "ponte" até a obtenção de um órgão adequado ${ }^{1}$.

Existem basicamente dois sistemas de assistência hepática: o fígado bioartificial externo ou bioreator e o fígado bioartificial implantável. O princípio de funcionamento do bioreator assemelha-se a hemofiltração através de membrana biocompatível contendo hepatócitos. O fígado bioartificial consiste na implantação de hepatócitos isolados no fígado, no baço, ou no peritônio. O peritônio oferece como vantagens maior espaço para acomodá-los com superfície ideal para trocas metabólicas. Para que os hepatócitos permaneçam viáveis e funcionais no peritônio devem, obrigatoriamente ser previamente fixados sobre suportes, ou colocados em cápsulas ${ }^{2-5}$.

Com a perspectiva de desenvolvimento do fígado bioartificial implantável em humanos ${ }^{6}$, foi aplicada a técnica de encapsulação de hepatócitos de roedores em hepatócitos humanos. Porém observaram neste trabalho, perda precoce de determinados fatores de diferenciação dos hepatócitos

1. Coordenador do Programa de Transplante Hepático e Pancreático do Hospital e Maternidade Angelina Caron (HAC), Campina Grande do Sul - PR; Mestre em Transplantes, Université Paris XI; Fellow Research Unité 402, INSERM - Faculté de Medicine Saint Antoine - Paris - France; Doutor em Cirurgia; Professor Adjunto da PUC-PR.

2. Coordenação de Ensino e Pesquisa do HAC; Doutor em Imunologia - Université de Paris VI

3. Chefe do Serviço de Urologia - Hospital de Clínicas - Universidade Federal do Paraná.

4. Coordenador do Programa de Pós-graduação em Clínica Cirúrgica, Setor de Ciências da Saúde - Hospital de Clínicas - Universidade Federal do Paraná.

5. Chefe do Serviço de Cirurgia Geral do HAC; Mestre em Clínica Cirúrgica pela Pontifícia Universidade Católica do Paraná.

6. Chefe do Serviço de Cirurgia Geral e Digestiva, Hôpital Saint-Antoine, Paris França. 
transplantados, o que levantou a hipótese de avaliar a real capacidade da fibra de encapsulação em proteger os hepatócitos transplantados contra a agressão imunológica do organismo receptor, uma vez que tratava-se de uma combinação filogenética extremamente discordante, homemrato.

Portanto, os objetivos do presente estudo são: averiguar a capacidade da fibra de encapsulação em proteger hepatócitos humanos transplantados em ratos, tendo como indicadores a diminuição da expressão gênica, a perda precoce de fatores de diferenciação, e se existem causas imunológicas envolvidas nestas perdas. Avaliar o ADN destas células, na procura de apoptose e determinar por RT-PCR a expressão do complexo maior de histocompatibilidade (CMH) de classe I nos hepatócitos transplantados, através do estudo do gene da $\beta_{2}$ microglobulina.

\section{MÉTODO}

\section{Delineamento experimental}

Este estudo foi realizado nos laboratórios de Cirurgia Experimental da Unidade U402 do Hospital Saint Antoine da Universidade de Paris VI - França.

As fases seguidas para atingir os objetivos propostos foram: isolamento de hepatócitos humanos, encapsulação e transplantação dos hepatócitos humanos isolados em ratos Lewis, eutanásia e coleta de amostras para as avaliações nos dias 3, 7 e 14 pós-implantação. Foram realizadas cinco séries experimentais, cada série comportando seis ratos, dos quais três recebiam três fibras com hepatócitos e outros três ratos recebiam uma fibra vazia (controle). Foram transplantadas três fibras com hepatócitos em cada rato do grupo experimento para que uma fosse destinada para avaliações morfológicas, e as demais para as avaliações de biologia molecular. O protocolo experimental foi aprovado pela Comissão de Ética do Hospital Saint Antoine.

\section{Animais}

Foram utilizados 30 ratos machos singênicos Lewis provenientes do Centro de Criação R. Janvier (Le Genest Saint-Ile, França), com pesos médios de $235 \mathrm{~g}$, como receptores de hepatócitos humanos encapsulados. Foram submetidos às mesmas condições ambientais e de manejo, dispondo de alimentação e água ad libitum antes e após o transplante.

\section{Isolamento de hepatócitos humanos}

Os hepatócitos foram isolados a partir de fragmentos hepáticos humanos, obtidos durante hepatectomias para ressecção de metástases ou tumores benignos hepáticos. Os hepatócitos foram isolados através de dissociação enzimática $^{7-9}$. Os fragmentos foram pesados e introduzidos quatro catéteres nos orifícios vasculares principais que se apresentavam em sua superfície. Os demais orifícios vasculares foram ocluídos com pontos de sutura. Na seqüência, foi feita a lavagem do sangue contido nestes fragmentos com 1 litro de solução tampão HEPES à $37^{\circ} \mathrm{C}$, com débito em torno de $10 \mathrm{ml} /$ $\mathrm{min} /$ cateter. A seguir era feita perfusão de $500 \mathrm{ml}$ de solução tamponada fosfatada com colagenase, em débito de $5 \mathrm{ml} / \mathrm{mi}$ nuto/cateter.

No final, os fragmentos de fígado foram colocados em placa de Petri contendo meio de cultura L-15 Leibovitz enriquecido (SIGMA ${ }^{\circledR}$ - L4386) à temperatura de $37^{\circ} \mathrm{C}$. A cápsula de Glisson foi removida e os hepatócitos separados lentamente por agitação moderada. Eram então lavados duas vezes em meio de cultura L-15 enriquecido, contendo $0,2 \%$ (p/v) de Albumina Bovina (SIGMA®- A2153), 10.000UI/1 de PenicilinaG, 10mg/l de Estreptomicina, $2 \mathrm{mM}$ de Glutamina (SIGMA®- G9003), 100mUI/l de Insulina, 26mM de $\mathrm{NaHCO}_{3}$ e $10 \%$ de Soro Fetal Bovino (SIGMA®- C5155). Foram realizados dois ciclos de centrifugação à 600rpm. A fim de eliminar as células mortas e aumentar a pureza celular os hepatócitos foram diluídos em solução contendo 1 volume do meio de cultura, 0,9 volume de Percoll e 0,1 volume de PBS 10X concentrado, e então centrifugados à $3000 \mathrm{rpm}$, durante 8 minutos a $4^{\circ} \mathrm{C}$. As células hepáticas foram contadas com o auxílio de célula de Malassez e sua viabilidade foi analisada pelo teste de exlusão com Eritrosina. A partir do isolamento de mais de $120 \times 10^{10}$ hepatócitos viáveis, dava-se continuidade ao experimento.

\section{Encapsulação}

O material de encapsulação era composto por uma fibra de hidrogel, com diâmetro interno de $0,8 \mathrm{~mm}$, espessura de $0,1 \mathrm{~mm}$ e comprimento de $2 \mathrm{~m}$, desenvolvida a partir da membrana de diálise AN- 69 (Societé Hospal, R et D. Int, France). A fibra foi obtida pela coextrusão de solução contendo $6 \%$ do polímero AN-69 (Poliacrilonitrilo-metalilsulfonato de sódio), 91\% de dimetil-sulfoxida (DMSO) e 3\% de soro fisiológico. O hidrogel obtido pela separação das fases desta solução em soro fisiológico contém $83 \%$ de água. A permeabilidade das fibras medidas por difusão é de $83 \%$ para a albumina, de $13 \%$ para os IgG e nula para $\operatorname{IgA}$ e IgM. A porosidade é estimada entre 150 e $165 \mathrm{kDA}^{11}$. Sob câmara de fluxo laminar, as fibras foram descontaminadas durante $20 \mathrm{mi}-$ nutos em Dialox (Solução de ácido paracético a 3\%), diluído à $10 \%$ em soro fisiológico e posteriormente enxagüadas em soro fisiológico. A eliminação do Dialox foi controlada com papel iodado. A suspensão celular, contendo $1 \times 10{ }^{12}$ hepatócitos $/ \mathrm{ml}$ foi introduzida em dois metros de fibra através de cateter venoso 22G. As cápsulas eram ocluídas em suas extremidades com clip cirúrgico e posteriormente depositadas em meio de cultura L15 enriquecido e conservados por uma hora em estufa com $95 \%$ de ar ambiental e $5 \%$ de $\mathrm{CO}_{2}$, até a oportunidade do transplante.

\section{Procedimento cirúrgico para implantação intra-ab- dominal de hepatócitos encapsulados}

Os animais, foram anestesiados por inalação com éter sulfúrico e submetidos à laparotomia mediana e implantação na cavidade peritoneal de três fibras, cada uma contendo dez milhões de hepatócitos com viabilidade superior à 95\%, em cada rato do grupo experimento e uma fibra com meio $\mathrm{L} 15$, em cada rato do grupo controle. Foi realizada profilaxia antibiótica per-operatória por via intra-peritoneal com 1000UI de penicilina e $1 \mathrm{mg}$ de estreptomicina. 


\section{Avaliação Morfológica}

A avaliação histológica foi realizada após coleta das fibras e sua fixação em solução de Carlson por três dias. Foi realizada a microscopia eletrônica em cortes de $0,5 \mathrm{~mm}$, corados por Azul de Toluidina e em cortes ultrafinos de $600 \mathrm{~A}^{\circ}$, contrastados com acetato de uranila e chumbo, em microscópio eletrônico Zeiss EM 10. Foram assim avaliadas as morfologias dos hepatócitos, bem como possíveis células responsáveis pelo fenômeno da rejeição no interior das fibras de encapsulação.

\section{Extração deARN/ADN}

O processo utilizado para extração dos ácidos nucléicos baseou-se na absorção de ARN/ADN em coluna de silício (ARN/ ADN mini kit, Qiagen). A quantificação dos ácidos nucléicos foi medido pela densidade óptica (DO) à $260 \mathrm{~nm}$. Para se obter uma preparação de ARN pura, a relação DO 260/DO 280 deveria estar compreendida entre 1,8 e 2. A qualidade dos ARN/ADN obtidos era verificada sobre gel não desnaturante de Agarose a $1 \%$. No caso do ADN a verificação de sua qualidade sobre o gel demonstrava se os mesmo estava fragmentado ou não comprovando-se daí a apoptose celular.

\section{Reação em Cadeia da Polimerase (RT-PCR)}

Transcrição reversa do ARN: $1 \mu \mathrm{g}$ de ARN total foi "reversamente transcrito" em ADN complementar (ADNc) com a enzima transcriptase inversa Superscript ${ }^{\mathrm{TM}} 13$.

Amplificação do ADNc por PCR: a PCR foi realizada com $2 \mu \mathrm{l}$ de ADNc ao qual foi acrescentado $48 \mu \mathrm{l}$ de mix PCR contendo as sequências necessárias para a co-amplificação.

Detecção dos produtos amplificados: $9 \mu \mathrm{l}$ de produto de PCR, diluídos com um ml de azul polarizado foram depositados em um gel de agarose $2,5 \%$, contendo $0,5 \mu \mathrm{g} / \mathrm{ml} \mathrm{de}$ brometo de etidium para que se pudesse visualizar os produtos de PCR em luz ultra-violeta (UV).

Foram colhidos $5 \mu \mathrm{g}$ de RNA total para cada amostra e na seqüência misturados à $15 \mu \mathrm{l}$ de uma solução contendo $500 \mu \mathrm{l}$ de formamida deionisada, $178 \mu \mathrm{l}$ de formaldeído à $37 \% \mathrm{e}$ $100 \mu 1$ de um tampão fosfato $10 \mathrm{X}$ concentrado. Após desnaturação das estruturas secundárias à $68^{\circ} \mathrm{C}$, as amostras coradas com $2 \mu \mathrm{l}$ de azul de depósito $(0,25 \%$ xileno cianol, $0,25 \%$ azul de bromofenol, $50 \%$ glicerol, $1 \mathrm{mM}$ EDTA) foram depositadas sobre um gel de agarose formaldeído desnaturante.

\section{Método Estatístico}

Neste trabalho foram realizadas cinco séries representativas não comparáveis entre si. Portanto as variáveis quantitativas foram expressas sob forma de média \pm desvio padrão. No caso dos resultados do rendimento do isolamento dos hepatócitos antes e após gradiente de Percoll utilizou-se o teste de Wilcoxon sendo que considerou-se significativo quando $\mathrm{p} \leq 0,05$.

\section{RESULTADOS}

\section{Isolamento dos Hepatócitos Humanos}

O rendimento de hepatócitos isolados obtidos após

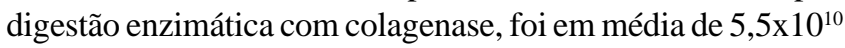

células vivas por grama de fígado, com viabilidade de $65 \%$ previamente ao gradiente de Percoll. Após a separação das células hepáticas vivas e mortas em Percoll foi observado aumento significativo da viabilidade $(\mathrm{p} \leq 0,03)$ porém com diminuição também significativa do rendimento $(\mathrm{p} \leq 0,03)$. A pureza da solução final contendo hepatócitos foi próxima de $100 \%$.

\section{Avaliação Morfológica do Hepatócitos}

Conforme demonstrado na Figura 1, no dia (D) zero, $2 \mathrm{~h}$ após encapsulação, $\mathrm{o}$ aspecto das células no interior das fibras em corte semi-fino era o de hepatócitos isolados normais, por vezes binucleados. Alguns começavam a aderir-se entre si e à parede das fibras de encapsulação. No dia 3 , maior quantidade de hepatócitos estavam em contato uns com os outros e aderiam à parede das fibras. As células formavam traves, organizadas em duas camadas. A análise ultra-estrutural mostrou núcleos com nucléolos presentes, estruturas citoplasmáticas bem conservadas com mitocôndrias e retículo endoplasmático granular intacto. A membrana plasmática formava microvilosidades e canalículos biliares podiam ser observados na junção das células (Figura 2). No sétimo dia de evolução, a maioria dos hepatócitos estavam bem conservados e organizados em traves pluricelulares aderentes à parede das fibras. Certas células $(<40 \%)$ em via de lise eram igualmente visíveis. No décimo quarto dia de evolução, a maioria das células estavam lisadas ou em via de lise com desaparecimento da membrana citoplasmática. Não foram observados sinais de apoptose (fragmentação e/ou condensação nuclear) nem de mitoses a D-3, D-7 ou D-14, tão pouco de linfócitos ou outros elementos celulares envolvidos nos fenômenos de rejeição do tipo celular.

\section{Qualidade dos ADN extraídos}

Após migração sobre gel de agarose foi observado uma intensidade constante das bandas nos dias D-0, D-3 e D-7 com uma diminuição do sinal a D-14. Não foram observados, quaisquer processos de fragmentação compatível com apoptose celular (Figura 3).

\section{Deteç̧ão do ARNm da albumina e da $b_{2} m$ através de RT-PCR semi-quantitativa}

Após várias tentativas foi determinado que a quantidade ideal de seqüências oligonucleotídicas da $\beta_{2} \mathrm{~m}$ deveria ser duas vezes mais elevadas que as da albumina. A Figura 4 representa os sinais obtidos após eletroforese dos produtos PCR durante uma cinética de amplificação, em um gel de agarose 2,5\% corado pelo BET. Demonstra-se que no D-0 o nível máximo do produto de amplificação do ARNm da albumina era atingido já a partir de 24 ciclos. Entre D-3 e D-7, o produto de amplificação era detectado já a 24 ciclos, porém o nível máximo só era atingido entre 28-30 ciclos. Enquanto que no D-14 o sinal era muito mais fraco, detectável unicamente a partir de 30 ciclos. Quanto ao sinal da $b_{2} m$ não havia modificação entre D0 e D-3, diminuía em D-7 e estava ausente em D-14.

Detecção do ARNm da albumina por Northern blot

Os resultados da análise dos ARNm da albumina (Figura 5) mostraram diminuição em relação a D-0, já a partir de 


\section{Figura 1}

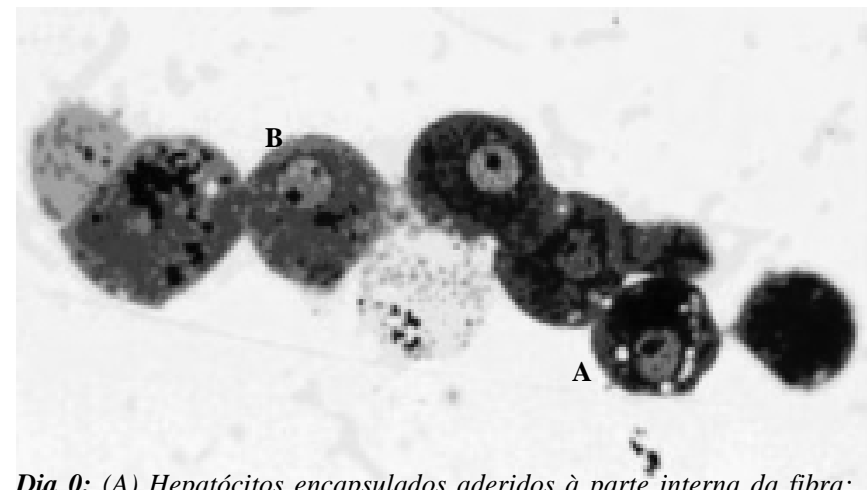

Dia 0: (A) Hepatócitos encapsulados aderidos à parte interna da fibra; (B) Hepatócitos Binucleados (1250x).

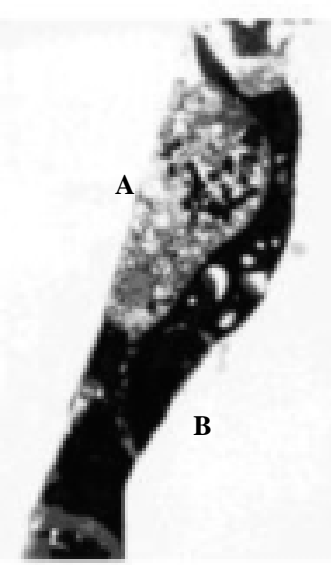

Dia 7: Hepatócitos encapsulados. (A) hepatócitos em lise. (B) hepatócitos viáveis (400x).

D-3, de maneira mais importante que observado nos resultados de RT-PCR.

\section{DISCUSSÃO}

Diferentes tipos de membranas de encapsulação foram desenvolvidos para proteger tanto células alogênicas quanto xenogênicas dos fenômenos de rejeição, a maior parte feitas de alginato ${ }^{14,15}$. Embora a sobrevida de células xenogênicas encapsuladas neste tipo de material tenha chegado a 29 dias foi difícil recuperar os hepatócitos microencapsulados da cavidade peritoneal e avaliar a sua viabilidade. Por este motivo foi utilizado, neste estudo, fibra de encapsulação de hidrogel (AN-69). A biocompatibilidade deste material já está bem estabelecida ${ }^{11}$ e a porosidade estimada entre 150 e $165 \mathrm{KDa}$ é maior que a do alginato usado para microencapsulação (porosidade estimada entre 50 a $120 \mathrm{KDa})^{16}$. Graças a esta maior porosidade, a maior parte das proteínas sintetizadas pelos hepatócitos podem ser liberadas através da membrana, com exceção apenas daquelas com grande peso molecular como o fibrinogênio, por exemplo, ao mesmo tempo que previne o contato direto das células transplantadas com o $\operatorname{IgM}$ e grande parte dos componentes do complemento do receptor ${ }^{11}$. Além disso, a recuperação pós-transplante deste tipo de material é simples e permite sem maiores dificuldades o estudo do material encapsulado. Poucos estudos relatam o transplante de hepatócitos humanos ${ }^{17-19}$. Em um destes estu-

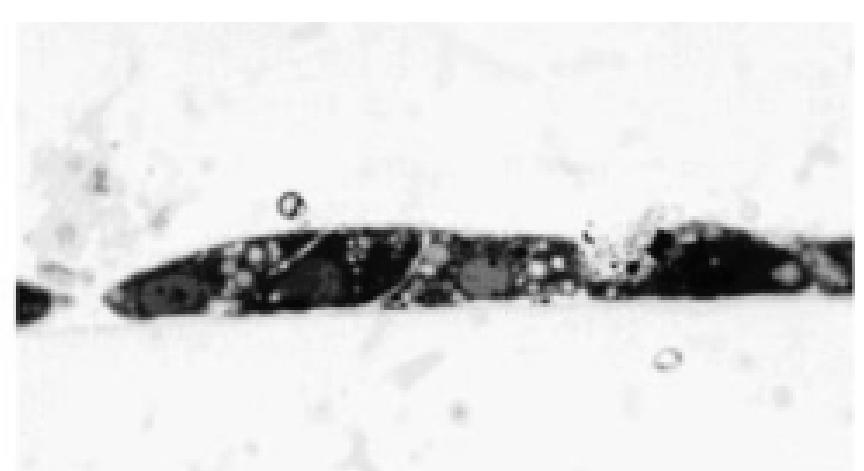

Dia 3: Hepatócitos organizados em camadas (400x).

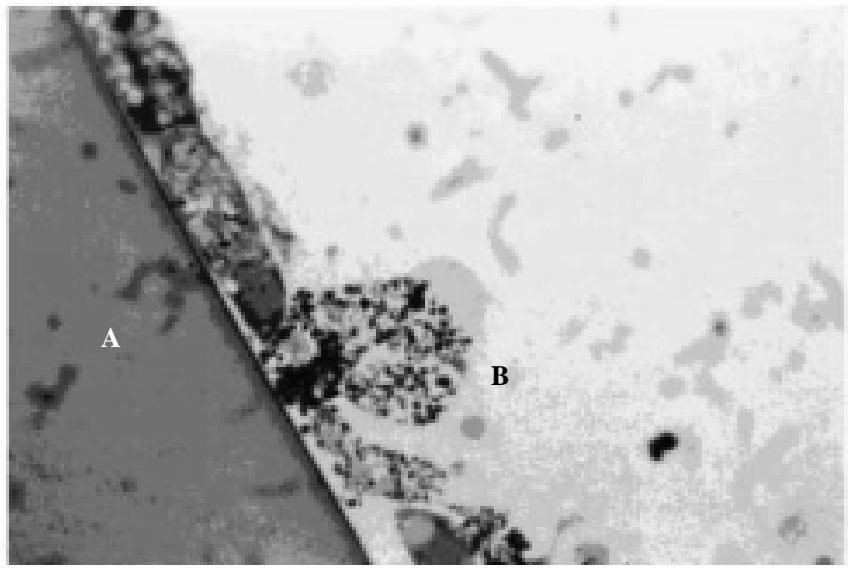

Dia 14: Hepatócitos encapsulados. (A) reação inflamatória na parte externa da fibra (B) hepatócitos em vias de lise (400x).

dos, as células hepáticas humanas foram isoladas a partir de segmentectomias e autotransplantadas sem imunossupressão em pacientes portadores de insuficiência hepática crônica. $\mathrm{O}$ sítio de implantação foi o baço no qual a persistência de hepatócitos foi evidenciada por scanner, sem que uma melhora clínica tenha sido demonstrada ${ }^{18}$. Em outro estudo, hepatócitos humanos transplantados sobre carreadores, permitiu a correção de deficiência enzimática em ratos Gunn

Figura 2

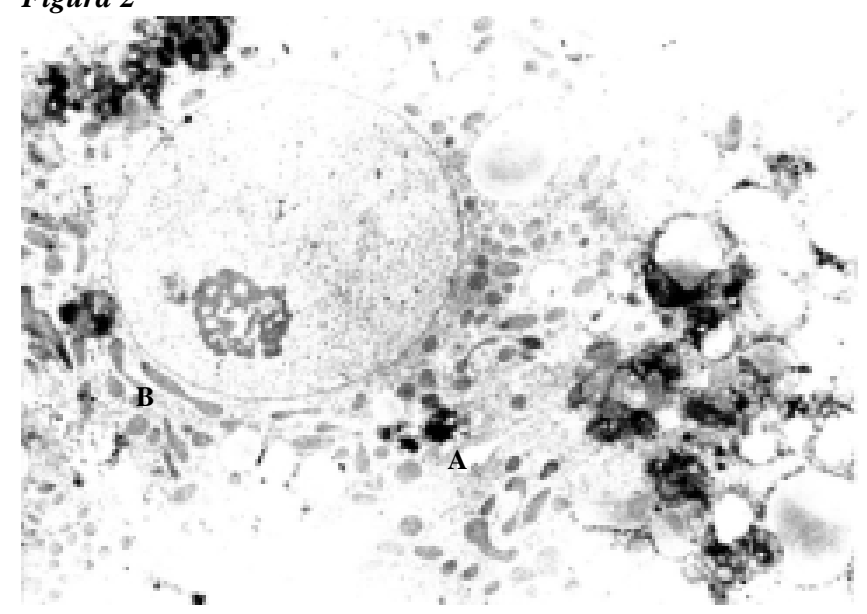

Dia 3: Fotomicrografia eletrônica de varredura de hepatócitos encapsulados demonstrando organelas intracelulares preservadas. (A) hepatócitos iniciando a formação de canalículos biliares. (B) Retículo endoplasmático rugoso (3150x). 


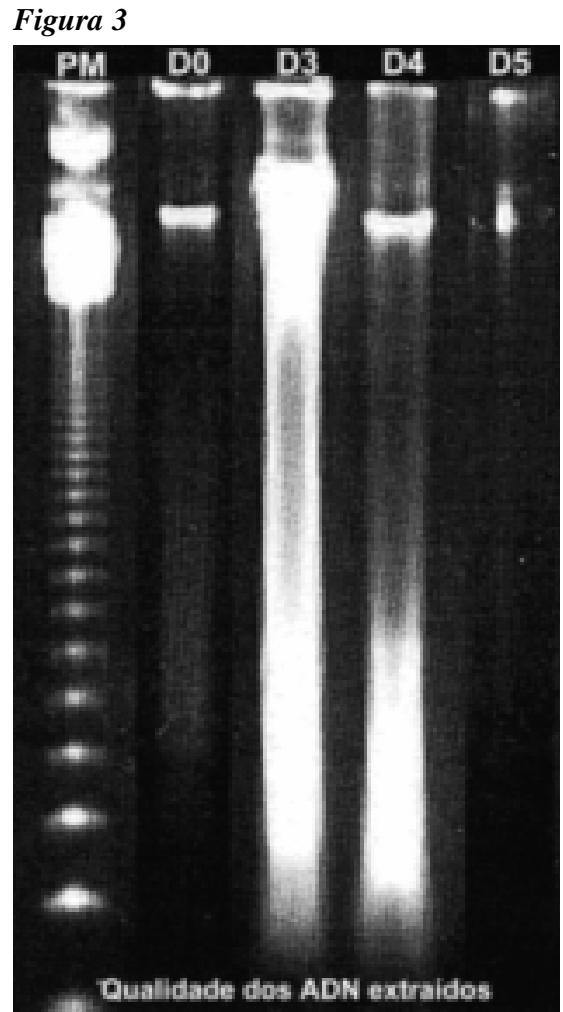

Dia (D): Peso Molecular (PM)
Figura 4

Ciclos

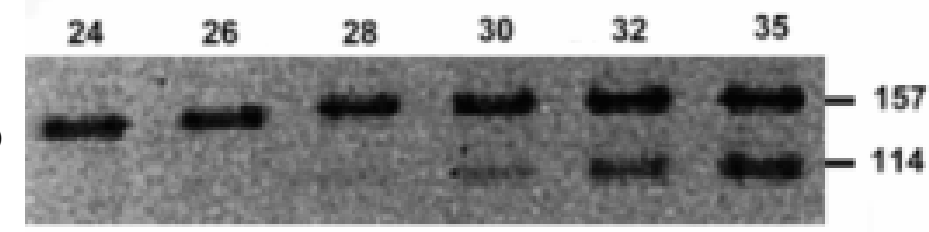

D3

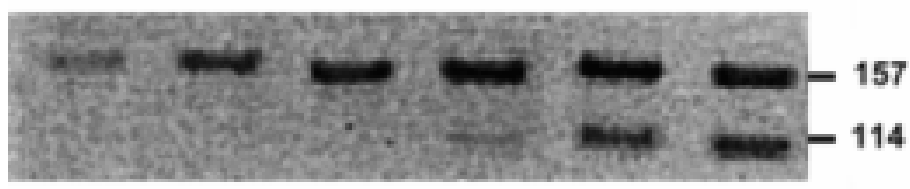

D7

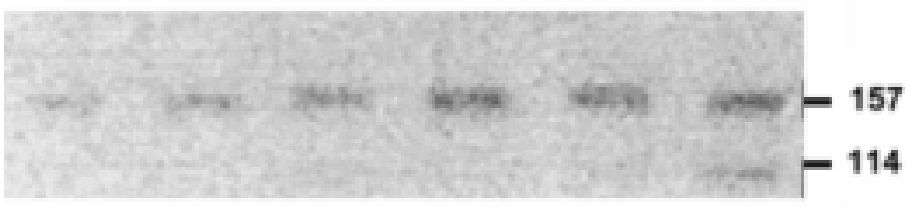

D14

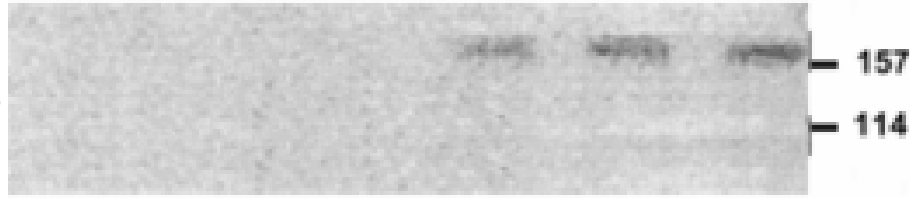

RT PCR para Albumina (157 pares de bases) e $\beta_{2}$ microglobulina (114 pares de bases)

dos hepatócitos expressarem baixos níveis de xenoantígenos ${ }^{10}$ eles são rapidamente destruídos, como foi demonstrado em um estudo anterior do laboratório, no qual estes quando injetados em ratos sem encapsulação foram totalmente destruídos em menos de sete dias ${ }^{16}$. Porém quando encapsulados, o mesmo trabalho demonstrou que mesmo 30 dias após o transplante eles ainda eram capazes de produzir albumina em cultura. Observou-se ainda que a partir de D-7 detectava-se a formação tanto de Ac anti-albumina humana, quanto antihepatócitos humanos, porém a membrana de encapsulação era capaz de protegê-los desta imunização por pelo menos 30 dias sem perda da sua função.

Este trabalho, pela primeira vez na literatura, serviuse de técnicas de biologia molecular para evidenciar o ataque do receptor contra as células humanas encapsuladas. Como

\section{Figura 5}

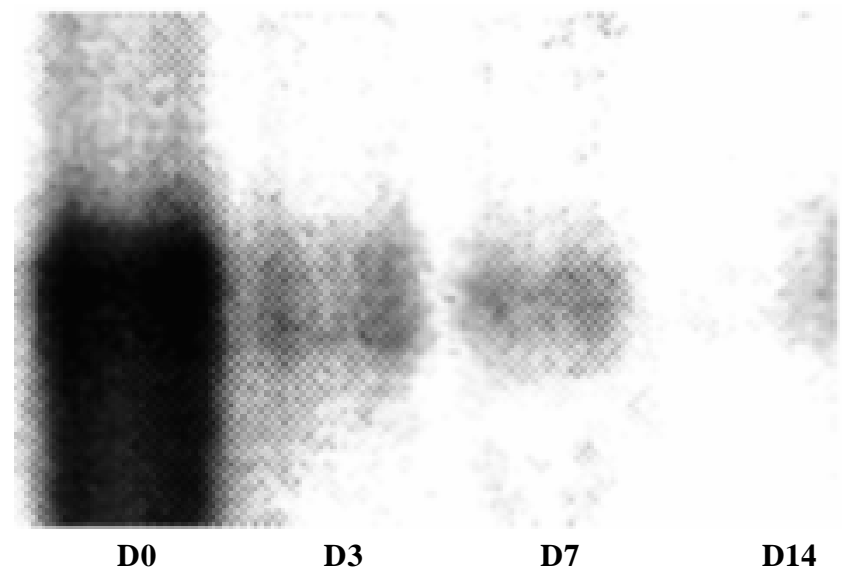

Detecção dos ARNm da albumina por Northern blot. 
visto, o ADN das células manteve-se íntegro por todo período de estudo comprovando a ausência de apoptose celular e indiretamente ausência de um mecanismo imunológico. Ainda em relação às moléculas do $\mathrm{CMH}$ de classe $\mathrm{I}$, as quais estão envolvidas no processo de apresentação de antígenos aos linfócitos T citotóxicos CD8+, geralmente só se exprimem nos hepatócitos em caso de estimulação ${ }^{10}$. O principal fator capaz de modular a expressão celular do CMH é a resposta imunológica, sendo o interferon do tipo g o principal mediador capaz de induzir as moléculas do CMH. Experimentalmente a rejeição do fígado se acompanha de forte expressão de moléculas do CMH: expressão de moléculas de classe I nos hepatócitos e de classe II nos canais biliares, e estas alterações aparecem progressivamente e são máximas no $7^{\circ} \mathrm{dia}^{1}$. No presente estudo observouse diminuição progressiva da expressão da $\beta_{2} \mathrm{~m}$, a qual é constituinte do CMH do tipo I e, portanto, este fenômeno observado não é condizente com resposta imunológica contra os hepatócitos humanos transplantados. A partir desses resultados, assim como dos resultados prévios da mesma equipe, verificou-se a ocorrência de um grau de imunização contra as células humanas encapsuladas, porém, este fenômeno, não é capaz de induzir à apoptose destas células, nem de prejudicar suas funções pelo menos a curto prazo.

Pensando-se na utilização deste modelo para períodos mais longos de necessidade, foi inicialmente sugerido que a resposta humoral não apresentaria efeito deletério mesmo em longo prazo na função de células xenogênicas como hepatócitos e ilhotas pancreáticas ${ }^{16}$. Porém recentemente um estudo demonstrou que associando-se um curto ciclo de imunossupressão com ciclosporina, eliminava-se a imunização contra hepatócitos xenogênicos e prolongava-se de maneira significativa a redução do colesterol sérico em coelhos Watanabe ${ }^{23}$. Em estudo do Laboratório de Cirurgia Experimental do Hôpital Saint-Antoine, utilizou-se hepatócitos humanos, derivados de linhagem celular do tipo HepG2, encapsulados e transplantados em ratos e submetidos a um curto ciclo de ciclosporina. Conseguia-se, assim, eliminar a imunização anteriormente demonstrada e prolongar suas funções por pelo menos 60 dias ${ }^{22}$. Estes resultados sugerem que existe um certo grau de dano crônico às células xenogênicas induzido pela resposta humoral ou por fatores solúveis liberados das células T ativadas. Portanto, a encapsulação pode previnir o contato direto entre células encapsuladas e anticorpos naturais IgM, assim como de componentes do complemento. A via indireta de apresentação do antígeno, porém, pode resultar na produção de anticorpos ou de mediadores inflamatórios que teriam efeito deletério na função hepatocitária após 30 dias do transplante ${ }^{22}$.

Observou-se discordância entre o bom aspecto das células encapsuladas e transplantadas, com os resultados da expressão do gene da albumina, os quais apresentaram uma queda significativa precocemente, principalmente no Northern blot. O que a princípio poderia ser creditado erroneamente a uma diminuição de viabilidade celular, deve-se, porém a uma reação da própria célula ao processo de isolamento celular. A ruptura das comunicações celulares leva a uma saída dos hepatócitos da fase de latência G0, na qual eles são mantidos in vivo e sua entrada na fase G1 do ciclo celular ${ }^{24}$, a qual se acompanha de uma diminuição da transcrição dos genes hepatocitários específicos. Teoricamente neste modelo deve ser possível estimular-se a proliferação hepatocitária como observado in vitro ${ }^{25}$. Vários estudos demonstraram aumento da proliferação de hepatócitos transplantados no baço ${ }^{26-30}$ ou sobre esponjas biodegradáveis após tanto uma hepatectomia à $70 \%$ quanto após injeção de fatores de crescimento por via exógena.

Este trabalho permitiu demonstrar que, em modelo xenogênico extremamente discordante, hepatócitos humanos encapsulados e transplantados em ratos sem imunossupressão, permanecem viáveis durante pelo menos sete dias. Durante este período os critérios estruturais de diferenciação se mantiveram. A expressão do gene de função hepatocitária de síntese se manteve ainda que com uma perda precoce em relação a D-0. Foi comprovado que este fenômeno não se deve a uma reação imunológica, mas provavelmente a uma reação da célula hepática ao traumatismo do isolamento celular. Resta determinar, agora que a questão imunológica foi respondida, como este modelo iria se comportar numa situação de insuficiência hepática aguda experimental antes de se passar à aplicação clínica.

\begin{abstract}
Background: Xenogeneic hepatocytes encapsulated in semipermeable membranes could be used in the future; however, encapsulated human hepatocytes presented an early decrease of hepatocyte gene expression. The objective of this study is to investigate the immunological consequences of intraperitoneal implantation of encapsulated xenogeneic hepatocytes on gene expression. Method: human hepatocytes were encapsulated in hollow fibers and transplanted in the peritoneal cavity of rats. The fibers were explanted for analysis at days D3, D7 and D14 following transplantation. Morphological features under light and electron microscopies and gene expression were compared to those of non-transplanted encapsulated hepatocytes. Human albumin mRNAs were quantified by RT-PCR and Northern blot. Immunological activity against human hepatocytes was assessed by the analysis of DNA searching for nucleolar apoptosis and also by the rise on MHC class I expression. Results: Transplanted hepatocytes were more than $60 \%$ viables and exhibited morphological criteria of hepatocytic differentiation up to D7. At no time cells involved with the immunological response were observed inside the fibers. Albumin transcripts were also detected up to D14. At D3 and D7, albumin mRNA levels were of $30 \%$, compared to control. The DNA analysis showed well preserved bands with no apoptosis at any time of evaluation. There was no rise on MHC class I expression. Conclusions: Human hepatocytes remain viable following encapsulation and intraperitoneal transplantation in rats. Although there is a decrease in gene expression this is not due to a host response against those cells. It seems that this effect is rather related to the process of hepatocyte isolation itself.
\end{abstract}

Key words: Live transplantation; Hepatocyte; Liver, artificial; Biocompatible materials. 


\section{REFERÊNCIAS}

1. Nordlinger B, Mariani P, Calmus Y - Transplantation d'hépatocytes isolés. Etat des connaissances actuelles et perspectives. Gastroenterol Clin Biol, 1994, 18(1):68-77.

2. Cai ZH, Shi ZQ, O'shea GM, et al. - Microencapsulated hepatocytes for bioartificial liver support. Artif Organs, 1988, 12(5):388-393.

3. Demetriou AA, Reisner A, Sanchez J, et al. - Transplantation of microcarrier-attached hepatocytes into $90 \%$ partially hepatectomized rats. Hepatology, 1988, 8(5):1006-1009.

4. Demetriou AA, Whiting JF, Feldman D, et al. - Replacement of liver function in rats by transplantation of microcarrier-attached hepatocytes. Science, 1986, 233(4769):1190-1192.

5. Fremond B, Malandain C, Guyomard C, et al. - Correction of bilirubin conjugation in the Gunn rat using hepatocytes immobilized in alginate gel beads as an extracorporeal bioartificial liver. Cell Transplant, 1993, 2(6):453-460.

6. Nicoluzzi JE, Barbu V, Baudrimont M, et al. - Viabilité et état de différenciation des hépatocytes humains immunoprotégés par macroencapsulation et transplantés chez le rat. Gastroenterol Clin Biol, 2000, 24(3):342-348.

7. Berry MN, Friend DS - High-yield preparation of isolated rat liver parenchymal cells. A biochemical and fine structural study. J Cell Biol, 1969, 43(3):506-520.

8. Seglen PO - Preparation of isolated rat liver cells. Methods Cell Biol, 1976, 13:29-83.

9. Fry JR - Preparation of mammalian hepatocytes. Methods Enzymol, 1981, 77:130-137

10. Calmus Y, Weill B, Poupon R - Expression hépatique des molecules du complexe majeur d'histocompabilité. Gastroenterol Clin Biol, 1991,15(2):110-119.

11. Honiger J, Balladur P, Mariani P, et al. - Permeability and biocompatibility of a new hydrogel used for encapsulation of hepatocytes. Biomaterials, 1995, 16(10):753-759.

12. Chang TM - Semipermeable microcapsules. Science, 1964,146:522-525.

13. Don RH, Cox PT, Wainwright BJ, et al. - "Touchdown" PCR to circumvent spurious priming during gene amplification. Nucleic Acids Res, 1991, 19(14):4008.

14. Dixit V, Darvasi R, Arthur M, et al. - Restoration of liver function in Gunn rats without immunosuppression using transplanted microencapsulated hepatocytes. Hepatology, 1990, 12(6):13421349.

15. Hirai S, Kasai S, Mito M - Encapsulated hepatocyte transplantation for the treatment of D-galactosamine-induced acute hepatic failure in rats. Eur Surg Res, 1993, 25(4):193-202.

16. Wen L, Calmus Y, Honiger J, et al. - Encapsulated xenogeneic hepatocytes remain functional after peritoneal implantation despite immunization of the host. J Hepatol, 1998, 26(6):960970.

17. Ballet F, Bouma ME, Wang SR, et al. - Isolation, culture and characterization of adult human hepatocytes from surgical liver biopsies. Hepatology, 1984, 4(5): 849-854.
18. Mito M, Kusano M, Kawaura Y - Hepatocyte transplantation in man. Transplant Proc, 1992, 24(6):3052-3053

19. Moscioni AD, Roy-Chowdhury J, Barbour R, et al. - Human liver cell transplantation. Prolonged function in athymic-Gunn and athymic-analbuminecmic hybrid rats. Gastroenterology, 1989, 96(6):1546-1551.

20. Balladur P, Crema E, Honiger J, et al. - Transplantation of allogeneic hepatocytes without immunosuppression: long-term survival. Surgery, 1995, 117(2):189-194.

21. Gomez N, Balladur P, Calmus Y, et al. - Evidence for survival and metabolic activity of encapsulated xenogeneic hepatocytes transplanted without immunosuppression in Gunn rats. Transplantation, 1997, 63(12):1718-1723.

22. Wen L, Grude P, Conti F, et al. - Supression of humoral immunization against encapsulated xenogeneic hepatocytes and prolongation of their function by 2-week cyclosporine treatment in the rat. Surgery, 2000, 127(3):301-308.

23. Gunsalus JR, Brady DA, Coulter SM, et al. - Reduction of serum cholesterol in Watanabe rabbits by xenogeneic hepatocellular transplantation. Nat Med, 1997, 3(1):48-53.

24. Ilyn G, Loyer P, Corly A, et al. - 'Prolifération et maintien des activités fonctionnelles des hépatocytes in vitro". In Dans Ilyn G, Loyer P, Corly A, et al. - Prolifération et maintien des activités fonctionnelles des hépatocytes in vitro. Paris, Inserm, 1998, pp.161-169.

25. Block GD, Locker J, Bowen WC, et al. - Population expansion, clonal growth, and specific differentiation patterns in primary cultures of hepatocytes induced by HGF/SF, EGF and TGF a in a chemically defined (HGM) medium. J Cell Biol, 1996,132(6):1133-1149.

26. Gupta S, Johnstone R, Darby H, et al. - Transplanted isolated hepatocytes: effect of partial hepatectomy on proliferation of long-term syngeneic implants in rat spleen. Pathology, 1987, 19(1):28-30.

27. Jirtle RL, Michalopoulos G - Effects of partial hepatectomy on transplanted hepatocytes. Cander Res, 1982, 42(8):3000-3004.

28. Jiang B, Sawa M, Yamamoto T, et al. - Enhancement of proliferation of intrasplenically transplanted hepatocytes in cirrhotic rats by hepatic stimulatory substance. Transplantation, 1997, 63(1):131-135.

29. Maganto P, Traber PG, Rusnell C, et al. - Long-term maintenance of the adult pattern of liver specific expression for $\mathrm{P} 450 \mathrm{~b}, \mathrm{P}$ 450c. albumine and alpha-fetoprotein genes in intrasplenically transplanted hepatocytes. Hepatology, 1990, 11(4): 585-592.

30. Nordlinger B, Mariani P, Calmus Y - Transplantation d'hépatocytes isolés. Etat des connaissances actuelles et perspectives. Gastroenterol Clin Biol, 1994, 18(1):68-77.

Endereço para correspondência:

Dr. João Eduardo Nicoluzzi

Rua: Santo Amaro, 118 - Água Verde.

80620-3320 Curitiba - PR

E-mail: jenicoluzz@yahoo.com 